\title{
Using Historical Data of Economic Variables in Investigating Variations in Building Construction Cost Index
}

\author{
Neslihan Atabeyli ${ }^{\mathrm{a}}$, Merve Kuru ${ }^{\mathrm{b}}$, Gulben Calis ${ }^{\mathrm{b}, *}$ \\ ${ }^{a}$ Dokuz Eylul University, Alsancak, Izmir, 35100, Turkey \\ ${ }^{b}$ Ege University, Alsancak, Izmir, 35100, Turkey
}

\begin{abstract}
The construction economy is exceptionally dynamic. Any variation in the prices of raw materials, labor, regulatory costs, and energy can have a major impact in the construction industry and make it difficult to control costs especially in large scale, long term and complex projects. Building Construction Cost Index (BCCI) is used in cost estimation of buildings and is defined as the measure of the changes in the cost of construction input items relative to the average price level of a base year. Therefore, it is important to understand the influencing factors and the impact of input variations in BCCI for limiting potential financial risks in construction projects. This study aims at investigating whether the historical data of different economic variables is useful to figure out the variations in BCCI. Data is obtained from the publications of the Turkish Statistical Institute to understand the relationship between BCCI and three factors including domestic producer price index, consumer price index and construction labor input index. In addition, the strength of the relationship between BCCI and aforementioned factors are analyzed via statistical analyses.
\end{abstract}

(C) 2018 The Authors. Published by Diamond Congress Ltd., Budapest University of Technology and Economics Peer-review under responsibility of the scientific committee of the Creative Construction Conference 2018.

Keywords: Building construction cost index; domestic producer price index; consumer price index; construction labor input index; statistical analyses.

\section{Introduction}

The statistics show that the total value of new U.S. construction between 2008 and 2017 is around 1.23 billion U.S. dollars and the estimated value of construction spending to Gross Domestic Prize (GDP) ratio is around 6.4\% in 2016 [1]. The fact that construction industry is one of the major industries in any country, it is important to estimate the total spending as well as the cost of input items that might change the overall spending in the construction industry. Therefore, several indexes have been introduced to estimate the construction costs. The Construction Cost Index (CCI) is defined as the weighted aggregate of average prices of constant quantities of common labour, standard structural steel, portland cement, and lumber whereas Building Construction Cost Index (BCCI) is defined as a measure of the changes in the cost of input items used in construction by periods. BCCI covers 12 items for labor cost and 109 items for material, which is one of the main inputs for estimating the building construction cost and budgeting of capital projects. Therefore, it is important to understand the influencing factors and the impact of input variations in BCCI. The aim of this study is to examine whether the historical data of different economic variables are useful to explain BCCI variations in Turkey. Historical data of 3 variables including Domestic Produce Price Index (DPPI), Consumer Price Index (CPI) and Construction Labor Input Index (CLII) are obtained from the publications of Turkish Statistical Institute (TSI) for the period between 2005 and 2017. Statistical analyses are conducted to investigate the relationship as well as the strength of the relationship between the variables and BCCI. 
The following sections present the research background and describe materials and methodology. Then findings are presented and discussed.

\section{Research Background}

Construction cost is still an unknown territory in which several variables might have direct or indirect effects, and, thus, investigating the effects of different variables on the CCI has received attention among researchers. Taylor and Bowen [2] analyzed the Index of Building Cost and concluded that the demand for construction has a dominant effect on the construction price level and construction supply capability has a long-term effect on the price movements. Skitmore [3] found a positive relationship between the new orders representing the construction demand and price level. Tender Price Index (TPI) also has been used as an indicator of construction cost level in the United Kingdom, Hong Kong, and Singapore [4]. Ng et al. [5] used the pattern of changes in eight explanatory variables (best lending rate, building cost index, consumer price index, gross domestic product, gross domestic product of construction industry, implicit gross domestic product deflation, money supply, and employment rate) for predicting the direction of changes in the Hong Kong TPI. Wong and NG [6] stated that the building cost index, gross domestic product, and gross domestic product in construction have explanatory value for predicting the TPI. Fellows [7] indicated that interest rates, investment intentions, architect's new commissions, production drawings, enquiries, orders, expected volume of work, and building cost can be the explanatory variables of the construction price in the U.K. Akintoye et al. [8] summarized unemployment level, construction output, industrial production, and the ratio of price to cost indices in manufacturing as the consistent leading indicators of the TPI.

In addition to understanding the parameters that influce the $\mathrm{CCI}$, there have been many studies carried out to forecast the variations in the CCI. Williams [9] used the trends in the CCI, prime lending rate, housing starts, and the months of the year as the inputs of back-propagation network models to predict changes in the CCI. It is concluded that the CCI prediction is a complex problem, and, thus, it cannot be accurately predicted by the neural network models. Ashuri et al. [10] conducted a research to empirically examine whether the time series information on the economic, energy, and market variables is useful to explain the CCI variations.The results of the study showed that the information available from historical data on consumer price index, gross domestic product, crude oil price, housing starts and employment level in construction is useful to explain variations of the CCI. Moreover, Ashuri and $\mathrm{Lu}$ [11] created univariate time series models to forecast the CCI whereas Shahandashti and Ashuri [12] used multivariate time series models to forecast the CCI. Hwang [13] proposed two dynamic univariate time series models to predict the CCI. Moon and Shin [14] concluded that Vector Error Correction Model (VECM) showed better predictive ability than a cointegrated vector autoregression model and the advantages of query frequency over conventional economic indices could prove to be beneficial for forecasting purposes. Zhang et al [15], created a network approach in which time series is firstly converted into a visibility graph and future values were forecasted relied on link prediction. The researchers concluded that the proposed method is efficient to provide considerably accurate CCI predictions. Although many researchers have investigated the CCI and TPI from different perspectives, there is still a lack of research with respect to understanding the BCCI that has 12 items for labor cost and 109 items for material affecting the index, and, thus, is more unpredictable than the CCI. Therefore, there is still a gap which investigates the most influential variables on the BCCI.

\section{Materials and Methodology}

\subsection{Data}

In this study, annual quarterly data of the BCCI, DPPI, CPI and CLII are taken into account and the data is gathered from the publications of the TSI for the period between 2005 and 2017. It should be noted that the TSI announces the results of the BCCI and the CLII to the public on the 20th day or consequent working day of the following month of the quarter. Therefore, the data with respect to the last quarter of the year 2017 was not published as of this study was conducted, and, thus, the authors were not able to include it in the study. It should be noted that the results of the DPPI and the CPI are monitored monthly by the TSI, however, the fact that other variables are provided quarterly, the aforementioned variables are also converted to quarterly values by calculating the average value of previous three months. The descriptions of three economic variables are summarized in Table1. 
Table 1. Description of Variables.

\begin{tabular}{|c|c|c|}
\hline Variable & ID & Description \\
\hline Domestic Produce Price Index & DPPI & $\begin{array}{l}\text { Domestic Producer Price Index is a measure of the change in the prices of goods } \\
\text { and services sold as output by domestic producers in a given reference period }\end{array}$ \\
\hline Consumer Price Index & CPI & $\begin{array}{l}\text { Consumer Price Index measures the changes of the current retail prices of goods } \\
\text { and services purchased by consumers over a given time period }\end{array}$ \\
\hline Construction Labor Input Index & CLII & $\begin{array}{l}\text { Construction Labor Input Index is a measure of employment which is defined as } \\
\text { the total number of persons who work in the observation unit, as well as persons } \\
\text { who work outside the unit who belong to it and are paid by it }\end{array}$ \\
\hline
\end{tabular}

\subsection{Methodology}

Statistical analyses were carried out to understand the relationship between the BCCI and three variables including domestic producer price index, consumer price index and construction labor input index as well as investigating the strength of these relationships.

Firstly, the scatter plots were created to understand whether there is a linear relationship between the variables. Then, the Shapiro-Wilk tests were conducted to evaluate the normality of variables. The results of both analyses were used to select the applicable correlation coefficient. If there is a linear relationship between variables and variables are normally distributed, the Pearson correlation coefficient will be selected. Therefore, the Pearson correlation coefficients were calculated both to understand the direction of the relationships and to measure the strength of the relationships.

\section{Findings}

To investigate the relationship, firstly, the scatter plots of the BCCI and three variables were created. Then, Shapiro-Wilk normality test were conducted. As can be seen in Figure 1, the BCCI has a linear relationship with the DPPI, CPI and CLII. Therefore, it can be said that there is a correlation between BCCI and other variables.
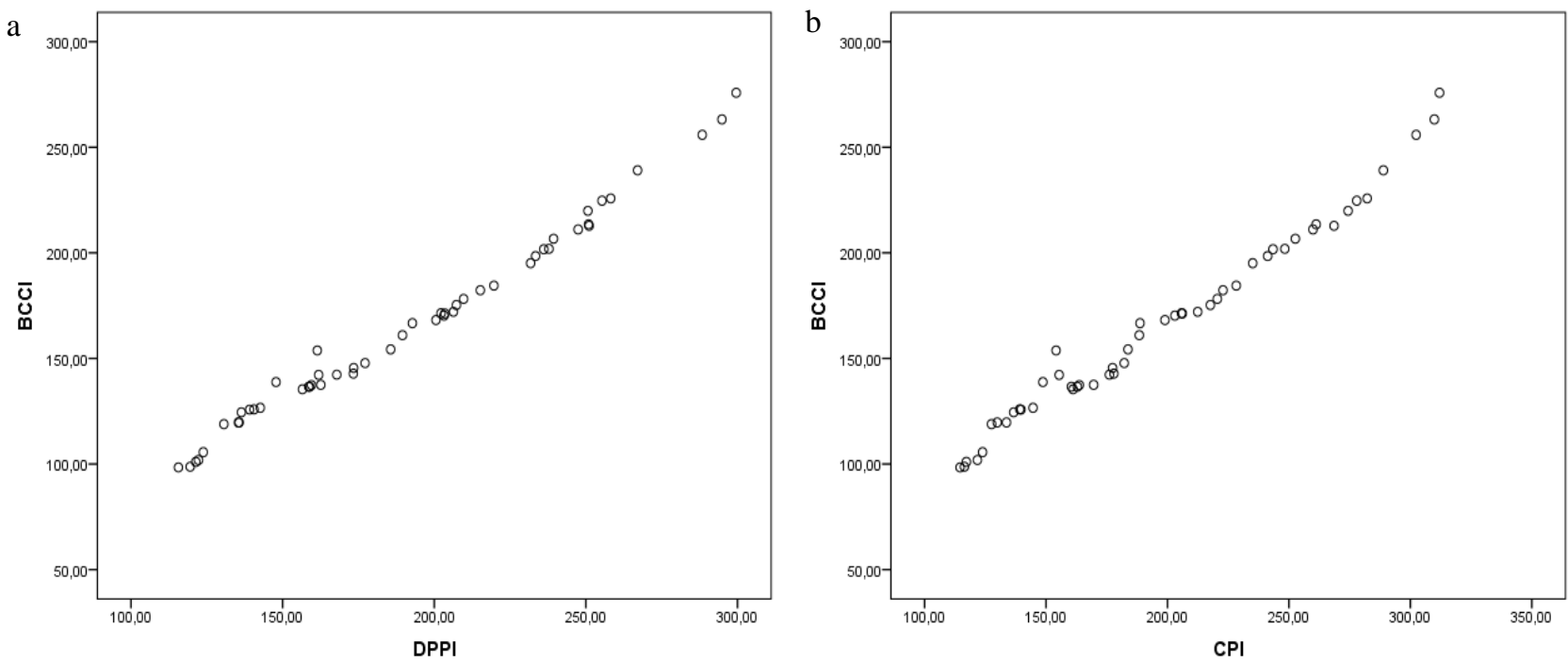
$\mathrm{c}$

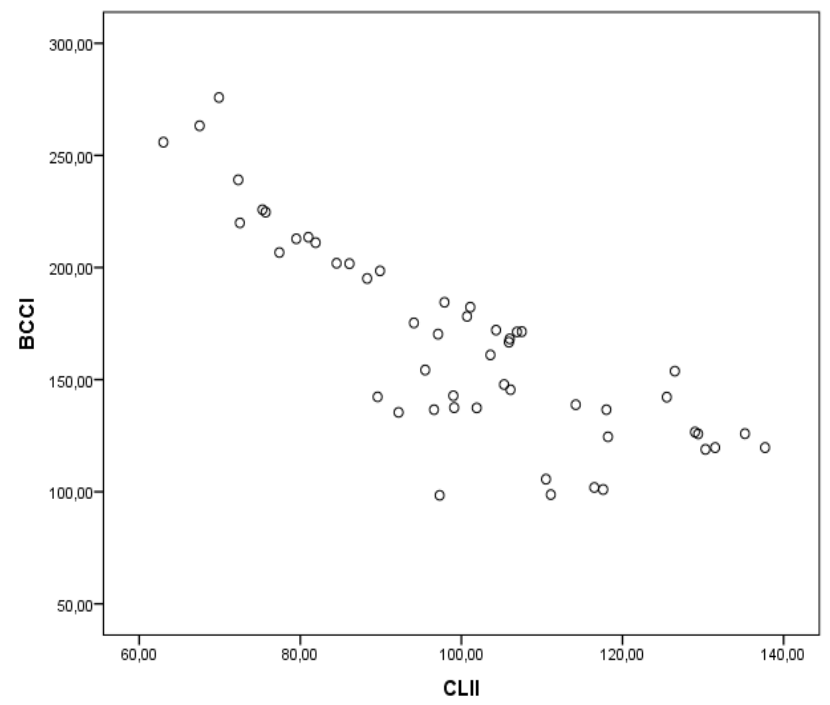

Fig 1. Scatter plot of the BCCI and (a) DPPI; (b) CPI; (c) CLII.

In order to select the applicable correlation coefficient, the Shapiro-Wilk tests were conducted to understand whether the variables distribute normally. The results of these tests are shown in Table 2. The results show that, the BCCI, DPPI and CLII are normally distributed at 0.05 significance level since their p-values are higher than 0.05 . On the other hand, the p-value of the CPI (0.033) is lower than 0.05 which indicate that the CPI is not normally distributed. However, since the sample size $(\mathrm{n}=51)$ in this study is bigger than 30 , it can be assumed that the distribution is normally distributed according to the Central Limit Theorem. The histograms of the BCCI, DPII, CPI and CLII with normal distribution curve are shown in Figure 2.

\begin{tabular}{cccc}
\multicolumn{1}{l}{ Table 2. The results of the Shapiro-Wilk tests. } \\
\hline \multicolumn{5}{c}{ Statistic } & df & Sig. \\
\hline BCCI & 0.959 & 51 & 0.074 \\
DPPI & 0.955 & 51 & 0.051 \\
CPI & 0.951 & 51 & 0.033 \\
CLII & 0.979 & 51 & 0.496 \\
\hline
\end{tabular}
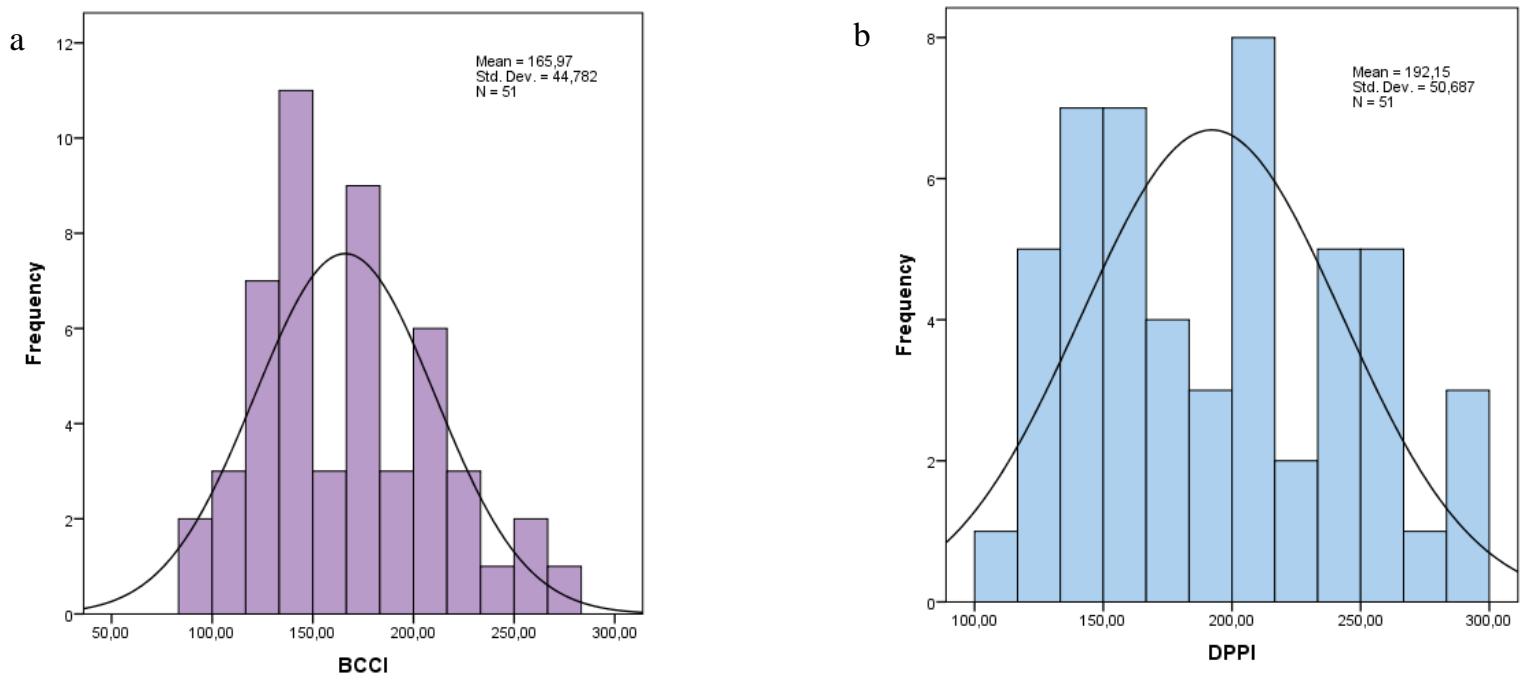
c

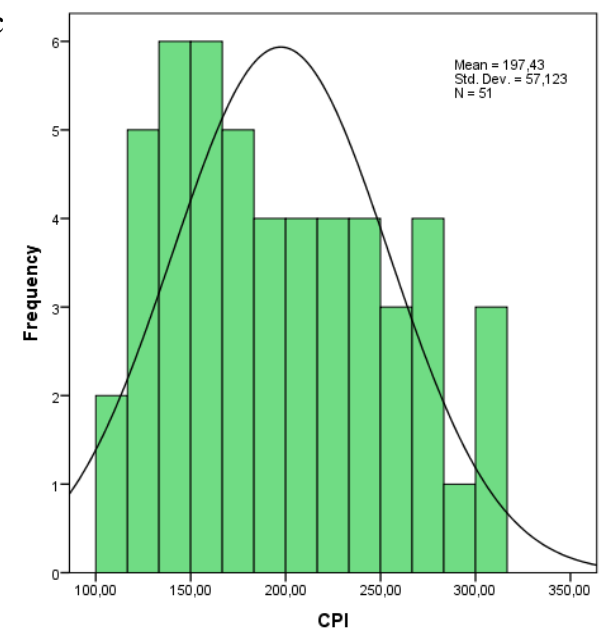

d

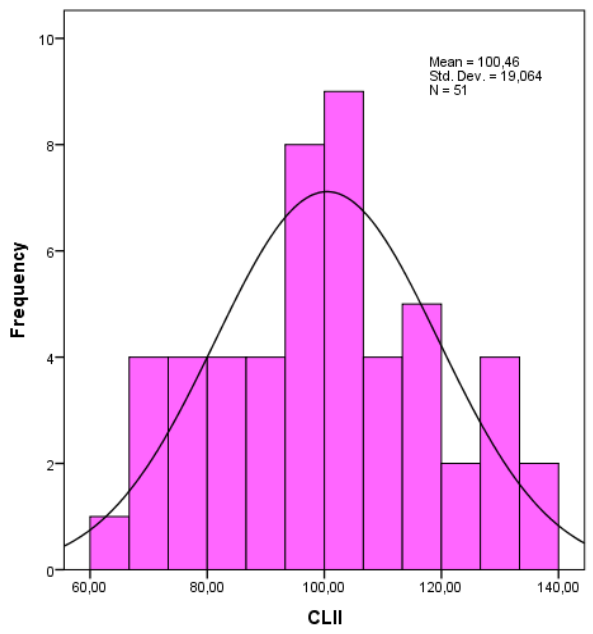

Fig. 2. The histogram with normality curve of (a) BCII; (b) DPII; (c) CPI; (d) CLII.

Since the variables are normally distributed, the Pearson correlation coefficients were calculated to understand the strength and the direction of the relationships between the BCII and three variables (DPPI, CPI and CLII). The Pearson correlation coefficients calculated at the 0.01 significance level are shown in Table 3.

\begin{tabular}{ccccc}
\multicolumn{5}{l}{ Table 3. The Pearson correlation coefficients. } \\
\hline & & DPPI & CPI & CLII \\
\hline \multirow{U}{*}{} & Pearson Correlation & 0.993 & 0.989 & -0.831 \\
& Sig (2-tailed) & 0.000 & 0.000 & 0.000 \\
$\mathbf{N}$ & 51 & 51 & 51 \\
\hline
\end{tabular}

The results show that the calculated Pearson correlation coefficients are statistically significant since their significance levels are lower than the 0.01 significance level. Moreover, the results indicate that there is a positive correlation between the BCCI and two variables including the DPII and CPI $(0.993>0 ; 0.989>0)$ whereas there is a negative correlation between the BCCI and CLII $(-0.831<0)$. In other words, when there is an increase in the DPII and CPI, the BCII also increases whereas when there is an increase in the CLII, the BCII decreases. The results also show that the BCCI has a very strong correlation with the DPPI, CPI and CLII since the calculated Pearson correlation coefficients are higher than 0.8 [16]. However, the closer the value is to 1 or -1 , the stronger the linear correlation. As a result, it can be said that relationship between the BCCI and DPPI is the strongest relationship (Table 4).

Table 4. Strength of relationships between the BCII and three variables

\begin{tabular}{ccc}
\hline & & Linear Correlation \\
\hline BCCI vs DPPI & Direction & Strength \\
BCCI vs CPI & positive & very strong \\
BCCI vs CLII & positive & very strong \\
\hline
\end{tabular}

\section{Conclusion}

As the BCCI is used in the cost estimation of buildings, it's important to understand the influencing factors and the impact of input variations in the BCCI. This study aims at investigating whether the historical data of different economic variables is useful to investigate the variations in the BCCI. The results of this study indicated that the 
BCCI has a very strong positive correlation with the DPPI and CPI. In other words, when there is an increase in the DPPI or CPI, BCCI also increases. Moreover the relationship between the BCCI and DPPI is the strongest relationship. On the other hand the BCCI has a very strong negative correlation with the CLII, which means that when there is an increase in the CLII, the BCCI also decreases. Future studies can extend the scope of this study by using more economical variables or construction indexes and also by predicting the future values of the BCCI using time series models.

\section{References}

[1] The Statistical Portal, 2017, https://www.statista.com/statistics/184341/total-value-of-new-construction-put-in-place-in-the-us-from-1999/ (accessed on 10.04.2018).

[2] R.G. Taylor, P.A. Bowen, Building price-level forecasting: an examination of techniques and applications, Construction Management and Economics. 5 (1987) 21-44.

[3] R.M. Skitmore, Construction market: The market effect, Royal Institution of Chartered Surveyors, Education Trust, Dept. of Civil Engineering, Univ. of Salford, Salford, UK, 1987.

[4] S.M. Rowlinson, A. Walker, The construction Industry in Hong Kong, Longman, Hong Kong, 1994.

[5] S.T. Ng, S.O. Cheung, R.M. Skitmore, K.C. Lam, L.Y. Wong, Prediction of tender price index directional changes, Construction Management and Economics. 18 (2000) 843-852.

[6] J.M.W. Wong, S.T. Ng, Forecasting construction tender price index in Hong Kong using vector error correction model, Construction Management and Economics. 28 (2010) 1255-1268.

[7] R.F. Fellows, Escalation management, Ph.D. thesis, Dept. Of Construction Management, Univ. of Reading, Reading, UK, 1988.

[8] A. Akintoye, P. Bowen, C. Hardcastle, Macro-economic leading indicators of construction contract prices, Construction Management and Economics. 16 (1998) 159-175.

[9] T.P. Williams, Predicting changes in construction cost indexes using neural networks, Journal Of Construction Engineering And Management. 120 (1994) 306-320

[10] B. Ashuri, S.M. Shahandashti, J. Lu, Is the Information Available from Historical Time Series Data on Economic, Energy, and Construction Market Variables Useful to Explain Variations in ENR Construction Cost Index?, Construction Research Congress 2012. (2012) 457-464.

[11] B. Ashuri, J. Lu, Time Series Analysis of ENR Construction Cost Index, Journal Of Construction Engineering And Management. 136 (2010) 1227-1237.

[12] S.M. Shahandashti, B. Ashuri, Forecasting Engineering News-Record Construction Cost Index Using Multivariate Time Series Models, Journal Of Construction Engineering And Management. 139 (2013) 1237-1243.

[13] S. Hwang, Dynamic regression models for prediction of construction costs, Journal Of Construction Engineering And Management. 135 (2009) 360-367.

[14] T. Moon, D.H. Shin, Forecasting Model of Construction Cost Index Based on VECM with Search Query, KSCE Journal of Civil Engineering. (2017) 1-9, 10.1007/s12205-017-0897-y.

[15] R. Zhang, B. Ashuri, Y. Shyr, Y. Deng, Forecasting Construction Cost Index based on visibility graph: A network approach, Physica A. 493 (2018) 239-252.

[16] J.D. Evans, Straightforward Statistics For The Behavioral Sciences, CA: Brooks/Cole Publishing, Pacific Grove, 1996. 